\title{
Long term thermal energy storage with stable supercooled sodium acetate trihydrate
}

\author{
Dannemand, Mark; Schultz, Jørgen M.; Johansen, Jakob Berg; Furbo, Simon
}

Published in:

Applied Thermal Engineering

Link to article, DOI:

10.1016/j.applthermaleng.2015.08.055

Publication date:

2015

Document Version

Peer reviewed version

Link back to DTU Orbit

Citation (APA):

Dannemand, M., Schultz, J. M., Johansen, J. B., \& Furbo, S. (2015). Long term thermal energy storage with stable supercooled sodium acetate trihydrate. Applied Thermal Engineering, 91, 671-678.

https://doi.org/10.1016/j.applthermaleng.2015.08.055

\section{General rights}

Copyright and moral rights for the publications made accessible in the public portal are retained by the authors and/or other copyright owners and it is a condition of accessing publications that users recognise and abide by the legal requirements associated with these rights.

- Users may download and print one copy of any publication from the public portal for the purpose of private study or research.

- You may not further distribute the material or use it for any profit-making activity or commercial gain

- You may freely distribute the URL identifying the publication in the public portal 
1 Title: Long term thermal energy storage with stable supercooled sodium acetate trihydrate.

2 Authors: Mark Dannemand, Jørgen M Schultz, Jakob Berg Johansen, Simon Furbo

3 Corresponding author email: markd@byg.dtu.dk

\section{Abstract}

Utilizing stable supercooling of sodium acetate trihydrate makes it possible to store thermal energy partly loss free. This principle makes seasonal heat storage in compact systems possible. To keep high and stable energy content and cycling stability phase separation of the storage material must be avoided. This can be done by the use of the thickening agents carboxymethyl cellulose or xanthan rubber. Stable supercooling requires that the sodium acetate trihydrate is heated to a temperature somewhat higher than the melting temperature of $58^{\circ} \mathrm{C}$ before it cools down. As the phase change material melts it expands and will cause a pressure built up in a closed chamber which might compromise stability of the supercooling. This can be avoided by having an air volume above the phase change material connected to an external pressure less expansion tank. Supercooled sodium acetate trihydrate at $20^{\circ} \mathrm{C}$ stores up to $230 \mathrm{~kJ} / \mathrm{kg}$. TRNSYS simulations of a solar combi system including a storage with four heat storage modules of each $200 \mathrm{~kg}$ of sodium acetate trihydrate utilizing stable supercooling achieved a solar fraction of $80 \%$ for a low energy house in Danish climatic conditions.

Utilizing the principle of stable supercooling of sodium acetate trihydrate makes it possible to store therma energy over long periods of time with minimal thermal losses. To keep-a high storage potential the phase separation of the salt hydrate must be avoided e.g. by use of a thickening agent. Stable supercooling requires that the sodium acetate trihydrate is heated to a temperature somewhat higher than the melting temperature of $58 \circ \mathrm{C}$ before it is cooled down. Expansion and contraction of the phase change material in a closed tank compromises the stability of the supercooling. An expansion device that allows for the phase change material to expand and contract without pressure changes in a closed chamber makes it possible to achieve stable supercooling. Initializing the crystallization of the supercooled sodium acetate trihydrate can be done by cooling the phase change material locally to the maximum level of supercooling or by mechanically providing a seed crystal. Supercooled sodium acetate trihydrate at $20^{\circ}-\mathrm{C}$ stores up to 230 $\mathrm{kJ} / \mathrm{kg}$ of thermalenergy. The energy discharged is affected by the storage temperature of the supercooled phase change material before crystallization and the final discharge temperature. Internal cavities are formed during the contraction of the phase change material when crystallizing decreasing the heat transfer rate. A thermally conductive liquid that does not mix with the phase change material can be added to fill the cavities and enhance the heat transfer. Graphite powder can improve the thermal conductivity of the sodium acetate trihydrate and needs to be kept dispersed evenly in the phase change material by a thickening agent that is stable at the maximum temperature of the storage during the charging. A TRNSYS simulation of a solar thermal combi system including a storage utilizing stable supercooling of sodium acetate trihydrate elucidates the system size to achieve $80 \%$ solar fraction of the low energy house in Danish climatic conditions.

Keywords: Compact seasonal heat storage; long term thermal energy storage; phase change material; PCM; supercooling, sodium acetate trihydrate.
Formatted: Font: Not Bold

Formatted: Font: Not Bold

Formatted: Font: Not Bold 


\section{Introduction:}

Space heating of buildings and domestic hot water supply account for a large part of our energy use. Solar energy is more abundant in summer than in winter periods when heating demands are much larger. Thermal energy storage technologies are therefore needed to match the intermittent supply of solar energy with varying heating demands if solar heating systems should fully cover our heat demand. Currently available heat storage systems that use water as the storage medium work well but mainly for short term storage, as their continuous heat losses limit the storage period. With a very large water storage, it is possible to store heat enough for a whole winter for a single family house but implementation is limited due to practicalities. For long storage periods in compact storages alternative technologies are needed. For this study long term storage is considered as biannually or longer periods which are required for seasonal heat storage.

Heat storages utilising latent heat of fusion of a phase change material (PCM) has been suggested for improving the performance compared to heat storage of sensible heat by several authors. Sharma and Sagara made an extensive review on latent heat storage materials and systems [1]. Nkwetta et al. did a review on the experimental and theoretical studies including PCMs in storages and solar collectors [2]. Sharif et al. also did a review on application of PCM for hot water and heating system [3] Sole et al. showed that including PCM in a water storage can improve its performance [4]. Wada et al. investigated several promising mixtures for solar energy storage [5]. Canbazoglu et al. investigated how hydrated salts can enhance the thermal energy storage performance of solar water heating systems [6]. Nagano et al. did experimental investigations in a latent heat storage considered for waste heat utilization and found that available enthalpy was more than double compared to a water storage [7]. López-Navarro et al. presented the design of a latent cold storage with a paraffin and characterized its performance [8]. Arce et al. elucidates how thermal energy storage can reduce energy consumptions with theoretical calculations [9]. Abhat introduces some fundamental considerations for both sensible and latent heat storages related to material properties and storage design [10].

Supercooling, subcooling or undercooling is when a phase change material in liquid state cools down below its melting point without solidifying; leaving it in a metastable state where the latent heat of fusion is not released. In latent heat storage supercooling has traditionally been seen as an undesired effect that had to be avoided as it prevented the heat of fusion from being released when the melting point of the storage material was reached during the discharge process [11]. This can be done by using various nucleation agents such as Aluminium Nitride Nanoparticles [12] or various salts [13]. The idea of utilizing supercooled salt hydrates for long term storage has however been known since the late 1920s [14] and pocket-sized heat packs storing heat in supercooled sodium acetate trihydrate were patented in 1978 [15]. This principle makes long term thermal energy storage possible by letting the melted salt hydrate remain in supercooled state at ambient temperature in the storage period. Once the heat is needed the solidification of the supercooled solution is triggered and the latent heat of fusion is released as it crystalizes. Investigations have previously shown that there is a potential in utilizing stable supercooling as a storage technique. Hirano and Saitoh showed by numerical simulations that latent heat storages utilizing supercooling have higher efficiencies than latent heat storages not utilizing supercooling and that the efficiency increases with longer storage periods [16] and is effected by the operating temperature [17]. The same authors tested a storage unit utilizing supercooling of 36-39 kg PCM [18]. Sandnes and Rekstad made measurement of energy released from supercooled samples of salt hydrates and gives recommendation for storage design 
[19]. Barrett and Best showed that some PCM mixtures can remain in supercooled state well below its melting point [20][18].

Sodium acetate trihydrate has a melting point of $58^{\circ} \mathrm{C}$ and a relatively high heat of fusion of $264 \mathrm{~kJ} / \mathrm{kg}$ [21], supercool consistently down to temperatures well below $0^{\circ} \mathrm{C}$ [20][22]. Rogerson and Cardoso investigated the relation between nucleation pressure and temperature and found via experiments that sodium acetate trihydrate spontaneously crystalizes at $-14^{\circ} \mathrm{C}$ or lower [23]. Wei and Ohsasa investigated supercooling and solidification of sodium acetate and found that there may be a link between the time and level of heating above the melting point and the stability of the supercooling [24]. Wada also reports that SAT crystalizes at a temperature of $-30^{\circ} \mathrm{C}$ or below [25].- When considering the application of space heating and domestic hot water preparation and solar collectors as the heat source, sodium acetate trihydrate has suitable thermal properties as storage material for long term heat storage [26].

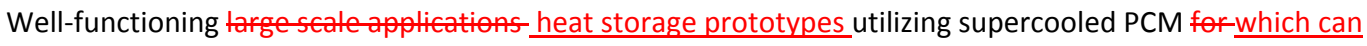
serve as seasonal heat storage for single family houses tong term storage-have not yet been reported. The primary barriers to achieve an operating storage based on stable supercooling of sodium acetate trihydrate are listed in this article along with proposed solutions. Suggested solutions are based on a series of laboratory experiments in small scale and on prototype storage modules. The theoretical storage potential for sodium acetate trihydrate is calculated based on a simple theory of specific heat capacities and latent heat of fusion of the PCM. A TRNSYS model simulating a solar combi system including a PCM storage utilizing stable supercooling of sodium acetate trihydrate covering the heat demand for a passive house in Danish climatic conditions elucidates the potential for the storage concept.

\section{Barriers, problems and solutions}

To achieve a reliable operating heat storage utilizing the principle of stable supercooling of sodium acetate trihydrate a number of problems need to be considered and solved. Problems are phase separation; expansion and contraction of the PCM during melting and solidifying, stable supercooling, heat transfer to and from the PCM and triggering the crystallization. In small sample sizes in closed bottles or jars the supercooling of sodium acetate trihydrate is usually reliable every time. When scaling up to larger sizes that are required to accommodate heating of buildings a number of problems occur. Dimensioning systems and storage sizes require stability of the performance of the PCM in every case. A series of small scale test with sample sizes of 200-500 g in glass jars and testing of prototype storages containing PCM masses of 100-220 $\mathrm{kg} \mathrm{kg}$ has led to the following focus points. These points have to be considered when designing a thermal energy storage based on stable supercooling of sodium acetate trihydrate.have been carried out in order to find solutions for these problems.

\subsection{Phase separation}

Sodium acetate trihydrate is an incongruently melting salt hydrate and will suffer from phase separation especially over repeated heating and cooling cycles. This will reduce the heat storage capacity as the energy released after crystallization of a supercooled sample is reduced when anhydrate sodium acetate segregates and settles to the bottom of the container so that the reformation of the trihydrate crystal is prevented as mentioned by Kimura [13] and Lane [14]. Furbo and Svendsen did extensive experimental testing of storages with salt hydrates $[27]_{\llcorner}[28]$. They suggest that Aadding extra water to the salt hydrate 
so the salt water mixture composition is always at a point where all salt is dissolved in the water when it is in liquid and supercooled state as a solution. This solution does however reduce the energy density of the storage as shown by Araki [28][29]. Also the melting temperature of the sodium acetate water mixtures will drop with increasing water content which may reduce the performance of the storage[30]. The extra water principle requires soft mixing of the salt water mixture to avoid phase separation which can possibly be achieved by the convection during heating, depending on the storage and heat exchanger design. However, as the phase separation happens mainly in the supercooled state before crystallization is triggered, there will still be a loss of latent heat of fusion when using the extra water principle for long term thermal energy storage with supercooling of sodium acetate trihydrate, if the mixing is not applied in another way.

Another method to solve the problem with phase separation is to add a thickening agent to the salt hydrate to keep the segregated salt from settling to the bottom of the container. Several additives such as carboxyl methyl cellulose (CMC) and Xanthan rubber have been researched previously. Hu worked with CMC [12]. Lane reports on some early research in search for cycling stable thickeners [14]. Cabeza et al. found starch and bentonite to be an appropriate thickener for sodium acetate trihydrate. Also Cellulose was tested but showed not to be stable above $65^{\circ} \mathrm{C}$ [31]. Wada et al. reports improvement of cycling stability of sodium acetate trihydrate when thickened with a mixture including polyvinyl alcohol [32]. Ryu et al. tested a super absorbent polymer and CMC as thickeners and found them effective [33]. Garay Ramirez et al. reports that a mixture of polymers of CMC and Silica Gel reduce phase separation [34].

Requirements for the thickening agent are inherently that it is stable over the temperature range of which the storage operates and the life time of the storage. The drawback of using thickening agents can be reduced storage density and reduced convection of the melted PCM in the storage, which will reduce the heat exchange capacity rate in the PCM during the charging process. In small scale tests $200 \mathrm{~g}$ samples were heated to $90^{\circ} \mathrm{C}$ in an oven until fully melted and let to passively cool to room temperature. A mixture of sodium acetate trihydrate and $1 \mathrm{wt} \%$ of CMC or $0.5 \mathrm{wt} \%$ for Xanthan rubber well mixed into the PCM has in small scale test shown to be sufficient to change the viscosity enough to keep anhydrate crystals suspended in the supercooled solution. Thickening agents may have viscosity changing ability varying over temperatures. To solve the phase separation problem with a thickening agent, it must be able to keep segregated salt suspended in in the supercooled state, not necessarily in the hot melted state where all salt is dissolved in the water.

\subsection{Density change Expansion of the PCM}

With a density of $1,280 \mathrm{~kg} / \mathrm{m}^{3}$ [26] [35] of the liquid sodium acetate trihydrate and $1_{L} 450 \mathrm{~kg} / \mathrm{m}^{3}$ of the solid, a volume difference of more than $10 \%$ has to be considered when designing the storage tanks. One problem related to this expansion is the strains it put on the storage tank during the heating and cooling cycling. The tank material should be able to withstand the pressure changes and deformations over the lifetime of the storage if this is not solved in another way. Testing of a prototype module in steel containing $100 \mathrm{~kg}$ sodium acetate trihydrate showed a pressure difference of 1.2 bars in the PCM chamber between the crystalized state at room temperature and the fully melted state at $90^{\circ} \mathrm{C}$.

A soft container for the PCM could be a solution if the container material can remain flexible over a life time of the storage. Also a flexibility of the connection for the storage may possibly be required. A rigid storage design with an expansion device that allows for the expansion and contraction of the PCM without pressure built up can eliminate the problems with changing strains in the storage tank material and possibly 
fatigue over time. In such system a fluid or gas can work as the medium going in and out of the expansion while the PCM stays in the primary chamber. The principle of how the expansion issue was solved for the prototype testing is illustrated in Figure 1 where an expansion vessel without pre-pressure is connected to an air volume above the PCM.

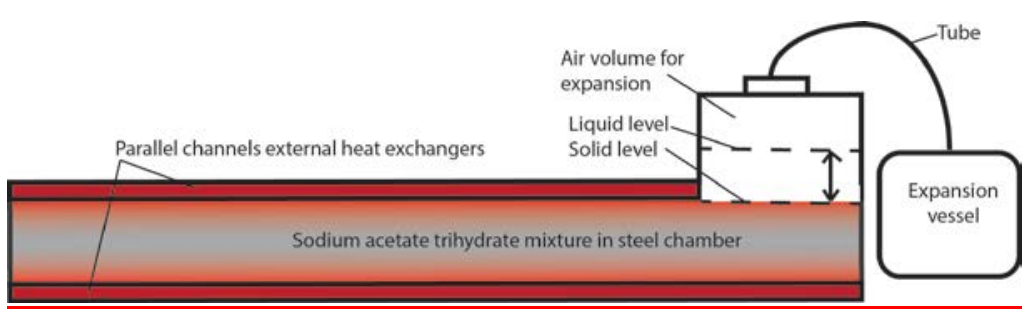

Figure 1. Principle of heat storage, module with expansion vessel to solve expansion of the PCM.

\subsection{Supercooling and cycling stability}

To achieve supercooling of the sodium acetate trihydrate it is necessary that all crystals of the bulk are melted so that it will not crystallise as it cools down. There appears to be a link between the level of heating above the melting point and the stability of supercooling as investigated by Wei [24] and Wada[36]. This was also investigated by Jin [37] who found that heating $8 \mathrm{~g}$ sodium acetate trihydrate in a test tube to

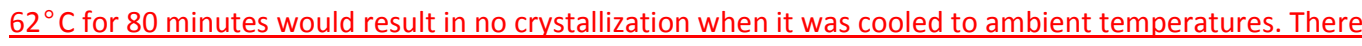
was no information if the samples crystalized after some time. Our investigations have shown that for Bboth small scale tests and prototype module tests showed a temperature of around $20 \mathrm{~K}$ above melting point in the entire volume helps to achieve stable supercooling over time. When the ever-present impurities in the salt hydrate work as nucleation agents, large PCM volumes may show reduced stability of supercooling, as the chance of a spontaneous nucleation caused by an impurity increases with the volume [38].

Heating the salt hydrate to a high temperature will cause some evaporation of the water; therefore a closed container with no loss of water through the tank material over the lifetime of the storage unit is essential to avoid changing the composition of the PCM. As the metastable state of the supercooled salt hydrate could easily be interrupted by external influences, a closed container is inherently more stable. Diffusion of the heat transfer fluid from the heat exchanger into the PCM should be avoided. When considering the choice of tank material, corrosion and chemical reactions between the salt and the tank material must be considered. Steel and stainless steel in combination with sodium acetate trihydrate has been shown to be stable over long periods as shown by Furbo et al. [27][28]. Cabeza et al investigated corrosion of metals immersed in salt hydrates and also recommends sodium acetate trihydrate in combination with steel and stainless steel [39].

If using rigid constructions such as steel the density change between the cold solid and the warm liquid salt hydrate must be considered, as the volume change of the PCM in a closed container can cause pressure changes and deformations of the tank. Just as bending a metal disk with cracks works as a triggering mechanism for the pocket sized heat packs by creating a local high pressure [40], small cracks on the inside of the PCM chamber can in combination with pressure changes and deformations work as an uncontrolled activation mechanism e.g. at joints or welds [41][42]. So if the storage tanks material is of rigid material
Formatted: Font: $9 \mathrm{pt}$, Font color: Accent 1, English (U.S.)

Formatted: Keep with next

Formatted: English (U.S.)

Formatted: English (U.S.)

Formatted: Caption

Field Code Changed

Formatted: English (U.S.)

Formatted: English (U.S.) 
operating it with constant pressure will provide better stability of the supercooling. Coating of inner surfaces to eliminate cracks or creating a softer inner surface may be a solution for rigid materials and at cracks and joints.

\subsection{Effective heat transfer from PCM to heat transfer fluid}

The volume reduction that takes place in sodium acetate trihydrate when changing from the liquid to the solid phase will form cavities inside the tank. These cavities will reduce the thermal conduction of the bulk PCM and heat exchange capacity rate between the PCM and the heat transfer fluid of the heat exchangers in a rigid storage [21][43]. Depending on the heat exchanger design these cavities could be a significant resistance in heat transfer as the cavities work as thermal resistances. Designing a soft container where the heat exchangers move along with the expansion and contraction of the PCM can be a solution but this requires a lot of the tank material in terms of flexibility and lifetime.

Another well-known problem of heat transfer in phase change materials is their low thermal conductivity [44]. To increase the heat transfer and the charge and discharge power of PCM storages, the thermal conductivity of the PCM has been sought increased by adding high conducting material such as graphite powder, expanded graphite or fibres to the PCM with good results. Heinz showed that adding graphite to a sodium acetate mixture will reduce the internal temperature difference in a sample especially during heating -[45]. Li et al. made investigations of the effect on adding expanded graphite to sodium acetate trihydrate [46]. Frusteri et al. showed that adding about $8 \%$ by volume graphite fibres can increase the thermal conductivity of a composite PCM by a factor of 4 [47]. Shin et al. investigated thermal properties of sodium acetate trihydrate mixed with expanded graphite and CMC [48]. Cabeza et al. investigated heat transfer enhancement in PCM thermal energy storages and found that a graphite matrix was very effective for heat flux enhancement [49]. Nkwette did numerical investigations showing the effect of having PCM integrated in a hot water storage. One of the investigated PCMs was sodium acetate trihydrate with $10 \%$ graphite [50]. A thickening agent that is stable for the operating temperature range which may be as high as up to $95^{\circ} \mathrm{C}$ is required to keep the graphite powder dispersed and evenly distributed in the PCM mixture and avoiding that the graphite powder segregates. Test with $300 \mathrm{~g}$ samples of sodium acetate trihydrate and fine graphite powder with up to $4 \% \mathrm{CMC}$ have shown that at a temperature of $90^{\circ} \mathrm{C}$ the thickening effect of the $\mathrm{CMC}$ is reduced and the graphite powder settles to the bottom. Samples with Xanthan rubber has shown to be stable in temperatures up to $90^{\circ} \mathrm{C}$.

When operating with supercooling and the rapid crystallization happening from supercooled state, the PCM may not contract in a uniform way and therefore cavities inside the PCM could form which would further enhance the problem of low conduction of the PCM. A high conductive liquid possibly oil that does not mix with the PCM and with a lower density so it floats on top when the PCM is in liquid state could work as an enhancer for the heat transfer. It could fill the cavities in the PCM and between the PCM and the heat exchanger. This would lead to a higher effective heat transfer when the PCM solidifies and contracts. This heat transfer liquid could possibly be considered when designing the expansion device. When the PCM is heated the oil can be pushed out to the expansion volume of the module.

With the low thermal conductivity of the PCM and no convection in the sold phase, the heat exchangers has to be designed to have good heat transfer, possibly by having large heat transfer areas short distances 
to the PCM. When designing the heat exchanger the requirements for a minimum temperature in all parts of the PCM to obtain supercooling should be considered.

\subsection{Triggering the crystallization}

As the entire volume will solidify once the crystallization is started, it is desirable to divide the storage unit into a number of separate modules that can be operated individually. The size and number of modules would depend on the application into which it is integrated and an economic evaluation.

The crystallization and release of the heat of fusion from the supercooled sodium acetate trihydrate is initialised when the first seed crystal of a certain size is present in the solution. From the point of activation the crystallization will spread to the entire volume and the temperature will rise to close to the melting point of $58^{\circ} \mathrm{C}$ [38]. Supplying the seed crystal to trigger the crystallization in a reliable and controllable way is essential for such a system. Ultra-sonic sound has been tried and found reliable as an activation mechanism [51]. The metallic disc of the pocket sized heat packs also works reliably but needs moving parts submerged in the solution and therefore introduce a risk of uncontrollable activation. Mechanically providing a crystal to the supercooled solution might also be a viable solution. Lastly, it has been shown that cooling supercooled sodium acetate trihydrate to a low temperature will eventually cause crystallization of the supercooled solution [22] [21\}. Experiments have shown that $100 \mathrm{~g}$ samples of sodium acetate trihydrate can stay supercooled down to temperatures of $-15^{\circ} \mathrm{C}$ to $-25^{\circ} \mathrm{C}$ before it crystalizes. Solutions where cooling is used to trigger the formation of the seed crystal could be made using peltier elements or cooling by the evaporation of liquid $\mathrm{CO}_{2}[21]$ [22]. One benefit of the cooling method is that there are no moving parts inside the PCM chamber and that reduces the risk of spontaneous crystallization. Evaporating liquid $\mathrm{CO}_{2}$ under pressure has a large cooling power and can be done through the tank wall from the outside of the tank. The loss of thermal energy by cooling can be considered negligible if just a tiny part of the PCM is cooled by a high cooling power. Cooling with $\mathrm{CO}_{2}$ has been a reliable activation technique in the prototype testing.

\section{Theoretical calculations:}

The theoretical energy content of the sodium acetate trihydrate is determined by the specific heat capacity of the solid and liquid phases as well as the latent heat of fusion. The following calculations assume an ideally performing material without losses due to phase separation; without problems related to stability of the supercooling, expansion of the PCM, heat transfer and triggering the crystallization. If these problems are not solved or only partly solved the performance will be worse that described. The theory describes the thermal energy content in a simple way, assuming that the sodium acetate trihydrate mixture behaves as an ideal compound that changes phase from solid to liquid at a specific melting temperature. In reality the phase change may happen over a temperature range especially if extra water is added to the salt hydrate[27]. When the focus is on the stable initial, fully charged, supercooled and discharged state, this simple theory provides a sufficient basis for estimation of energy content.

\subsection{Material storage potential}

The following equations show the theoretical change of thermal energy in the heat storage module for a given charge. The equation consists of the sensible heat of the salt hydrate in solid and liquid state, the latent heat of fusion of the salt hydrate and the sensible heat of the storage module material. 
$E_{\text {charge, theo }}=m \cdot\left(\left(T_{\text {melt }}-T_{\text {start }}\right) \cdot c_{p}(s)+L_{f}+\left(T_{\text {max }}-T_{\text {melt }}\right) \cdot c_{p}(l)\right)+C_{\text {module }} \cdot\left(T_{\text {max }}-T_{\text {start }}\right)$

where $m$ is the mass of the PCM, $T_{\text {melt }}$ is the melting temperature of the PCM of $58^{\circ} \mathrm{C}, T_{\text {start }}$ is the mean storage temperature at the start of the charge, $c_{p}(s)$ is the specific heat of the PCM in solid phase, $c_{p}(l)$ is the specific heat of the PCM in liquid phase, $L_{f}$ is the latent heat of fusion of the PCM, $C_{\text {module }}$ is the heat capacity of the storage module material including the heat transfer fluid in the heat exchangers, and $T_{\max }$ is the mean maximum temperature the heat storage module reaches during a charge.

When the storage module is discharged from the fully charged state at $T_{\max }$ to a temperature $T_{\text {supercool }}$ without crystallising, just the sensible heat of the module and the liquid sodium acetate mixture is discharged. Assuming the specific heat of the supercooled sodium acetate mixture is the same as the liquid sodium acetate mixture, the discharged energy $E_{\text {dis }}$ can be expressed by:

$E_{\text {dis,theo }}=\left(m \cdot c_{p}(l)+C_{\text {module }}\right) \cdot\left(T_{\max }-T_{\text {supercool }}\right)$

where $T_{\text {supercool }}$ is the storage temperature at supercooled state.

The stored thermal energy at supercooled state can be expressed using Eq. 3. Here the discharged energy expressed in Eq. 2 is subtracted from the charged energy expressed by Eq. 1.

$E_{\text {supercool,theo }}=E_{\text {charge,theo }}-E_{\text {dis,theo }}$

If the temperature of the storage module at supercooled state $T_{\text {supercool }}$ and end temperature $T_{\text {end }}$ after the activation and discharge are the same, then the thermal energy stored at supercooled state $E_{\text {supercool,theo }}$ at a temperature $T_{\text {supercool }}$ can be expressed by:

$E_{\text {supercool, theo }}=m \cdot\left(L_{f}-\left(T_{\text {melt }}-T_{\text {supercool }}\right) \cdot\left(c_{p}(l)-c_{p}(s)\right)\right)$

If the storage is discharged to a temperature that is different from that of the supercooled state, the discharged energy is corrected for the difference in sensible heat of the module material and the PCM mixture in solid state.

$E_{\text {correct, theo }}=\left(T_{\text {supercool }}-T_{\text {end }}\right) \cdot\left(C_{\text {module }}+m \cdot c_{p}(s)\right)$

The energy released per unit mass of PCM from activating a supercooled sodium acetate mixture at a specific temperature, corrected for a difference between the final discharge temperature and the temperature of the supercooled PCM mixture before activation is:

$E_{\text {cont, theo }}\left(T_{\text {supercool }}\right)=\frac{E_{\text {supercool,theo }}-E_{\text {correct,theo }}}{m}$

With the specific heat for the solid state sodium acetate trihydrate of $2.1 \mathrm{~kJ} / \mathrm{kgK}$ and $3.0 \mathrm{~kJ} / \mathrm{kgK}$ [29] for the liquid state, a latent heat of fusion of $264 \mathrm{~kJ} / \mathrm{kg}$ at the melting point of $58^{\circ} \mathrm{C}$; the energy content per unit of mass at a temperature range relevant for solar heating systems are displayed in Figure 2figure 1 . The listed specific heat capacities are averaged to a constant at the temperature range. In reality the specific heat capacities vary with temperature [29]. 


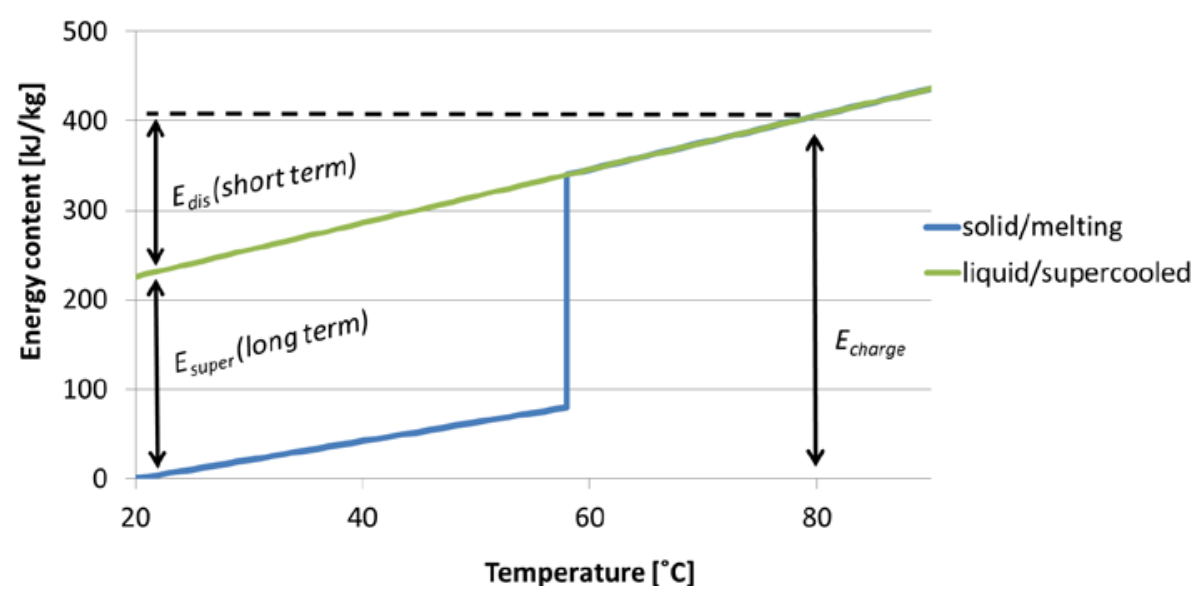

Figure 2. Principle of long term heat storage utilizing stable supercooling and storage potential for sodium acetate trihydrate.

\subsection{System performance by TRNSYS modelling}

A TRNSYS model [52] of a solar combi system with a PCM storage was used for a parametric study to determine the PCM storage size and solar collector area to obtain a solar fraction of $80 \%$ of the yearly heat demand for a passive house in Danish climatic conditions. The solar fraction (SF) was defined as

$S F=1-\frac{Q_{\text {aux }}}{Q_{S p a}+Q_{D H W}}$, where $\mathrm{Q}_{\text {aux }}$ is the auxiliary heating for the system, $\mathrm{Q}_{\text {Spa }}$ is the energy used for space heating and $\mathrm{Q}_{\mathrm{DHW}}$ is the energy used for domestic hot water (DHW) preparation. The $80 \%$ solar fraction was chosento

A principle diagram of the solar heating system design is shown in Figure 3 Figure 2

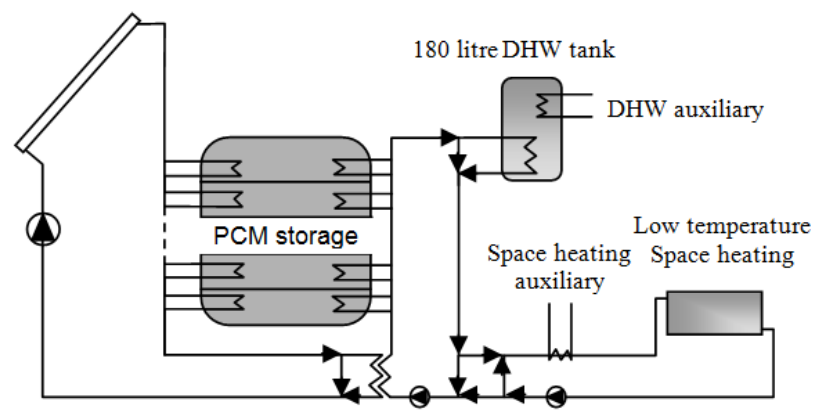

Figure 3. Principle diagram of TRNSYS model for solar heating combi system.

The system included the PCM storage and a 180 litres-L_DHW tank. The DHW tank was required to fulfil the power demand related to hot water draw offs, which would be difficult to fulfil with direct discharge of the PCM storage. Energy from the solar collectors could either be used for direct charge of the PCM storage or transferred to the demand loop through the heat exchanger connecting the solar collector loop and the demand loop. Here the energy could either be used for heating of the DHW tank or for space heating. The PCM storage was made up of a number of subsections that can be individually controlled with respect to

Formatted: Subscript
Formatted: Subscript
Formatted: Subscript


charging, discharging and activation of solidification. The sub sectioning of the PCM storage makes it possible to activate a small part of the total storage volume to match the demand and saving the rest of the supercooled sections for later activation. Previous analyses [48][53] have shown that the optimum control strategy for charging was first to heat up the DHW tank if the forward temperature from the collector was sufficient. When the DHW tank had reached a temperature of $70^{\circ} \mathrm{C}$ the PCM storage was thereafter charged one section at the time until fully melted if the forward temperature from the collector was high enough. Otherwise the section with the highest temperature that could be further heated was chosen. In case of space heating demand the necessary forward temperature to the space heating loop was secured by controlling the flow rate through the DHW heat exchanger if relevant or by discharging a section in the PCM storage that resulted in the necessary forward flow temperature to the heat exchanger. When discharging the PCM storage the section that just had the sufficient temperature for covering the actual demand was chosen. A supercooled section was activated if no liquid or solidified section had the required temperature level.

The PCM storage with sodium acetate trihydrate including the control had been modelled in a TRNSYS type and a series of parametric studies was carried out in TRNSYS with the system design shown in Figure 3 Figure 2 . The solar collectors were flat plate collectors with a start efficiency of $0.82,1$ st and 2 nd order heat loss coefficients of $2.44 \mathrm{~W} /\left(\mathrm{m}^{2} \cdot \mathrm{K}\right)$ and $0.005 \mathrm{~W} /\left(\mathrm{m}^{2} \cdot \mathrm{K}^{2}\right)$-respectively. The collectors were facing south with a collector tilt of $75^{\circ}$. The PCM storage and the DHW tank were in the reference case insulated corresponding to an effective heat loss coefficient of $0.4 \mathrm{~W} /\left(\mathrm{m}^{2} \cdot \mathrm{K}\right)$. The flow rate in the solar collector loop was set to $1,800 \mathrm{~kg} / \mathrm{hr}$. The heat exchange capacity rate between the PCM in the storage module and the heat transfer fluid is affected by the design of the heat exchanger and the properties of the PCM. Simulations with different values for heat exchange capacity rates are made to show how the system size is related to the heat exchange capacity rate. The heat exchange capacity rate for charge and discharge of the PCM storage was varied between 200 and $400 \mathrm{~W} / \mathrm{K}$ in this parameter variation. The volume of the modules was set to 150 liters.. The thermal conductivity of the PCM in both solid and liquid state was set to 0.6 $\mathrm{W} / \mathrm{mK}$. The daily DHW consumption was set to 99 liters_L/day (33 liters_L_draw off at 7.00, 12:00 and 18:00 respectively). The DHW temperature was $50^{\circ} \mathrm{C}$ and the cold water temperature was $10^{\circ} \mathrm{C}$ resulting in an annual DHW energy consumption of approximately $1,677 \mathrm{kWh}$. The space heating demand was calculated on hourly basis with the building energy simulation tool, tsbi3 [54] for a low energy house built according to the passive house standard [55] located in a Danish climate ( 3,000 degree days; horizontal solar radiation: $\sim 1,020 \mathrm{kWh} / \mathrm{m}^{2} /$ year). The space heating system was a low temperature system, e.g. floor heating with a heating demand of $2,008 \mathrm{kWh}$ per year.

Previous calculations [56] have been carried out simulating a low energy house with a heating demand of $2,010 \mathrm{kWh}$ per year and an annual DHW consumption of $2,540 \mathrm{kWh}$. The heat exchange capacity rate for charge and discharge of the PCM storage was $500 \mathrm{~W} / \mathrm{K}$ in these calculations. It was shown that it was possible to achieve a $100 \%$ solar fraction for a solar heating system with a $36 \mathrm{~m}^{2}$ collector area and $6 \mathrm{~m}^{3}$ sodium acetate trihydrate divided into 24 subsections. A Module size of 250 litres- $\underline{L}$ had showed to be the optimal size in this simulation. For this calculation it was assumed that that heat loss form the storage was utilized for space heating e.g. by having the storage located inside the building. Overheating of the house in the summer should be considered in this case. A PCM volume of $10 \mathrm{~m}^{3}$ was required if the losses were considers not utilized. The previous study showed that this volume was less than $25 \%$ of the required volume for a water storage to cover $100 \%$. 


\section{Results and discussion:}

Based on the theory in section 3.1 it is possible to store $230 \mathrm{~kJ} / \mathrm{kg}$ of thermal energy in a supercooled solution of sodium acetate trihydrate at a temperature of $20^{\circ} \mathrm{C}$ if it discharged to $20^{\circ} \mathrm{C}$ after crystallization. This assumes no losses due to phase separation. Activating the supercooled PCM at $15^{\circ} \mathrm{C}$ and discharging it to $30^{\circ} \mathrm{C}$ will release $194 \mathrm{~kJ} / \mathrm{kg}$. Some additional energy will in the case, where storage and final discharge temperature differs, be lost as it is used to heat up the storage tank material.

When operating with PCM in bulk sizes that are needed for storing enough energy for heating building and long storage periods, the material may act differently compared to small sample sizes. Phenomena like phase separation and local cavities resulting in thermal resistances may not be obvious in small sample sizes normally used in material characterization such as T-history and differential scanning calorimetry (DSC) measurements. The key material property for making a heat of fusion storage with supercooling is the latent heat of fusion as this determines the storage capacity. The highest heat of fusion for the sodium acetate trihydrate is assumed to be of the pure material if phase separation is avoided. Additives such as thickening agents for stabilizing the PCM or thermal conductivity enhancer will reduce the latent heat of fusion per unit of mass but may be necessary to have the system perform reliable.

\subsection{TRNSYS simulation}

The parametric studies carried out were aimed at achieving $80 \%$ solar fraction of both DHW and space heating in a passive house in a Danish climate. The heat exchange capacity rate of a PCM module will depend on multiple variables such as heat exchanger design and thermal properties of the PCM and heat transfer fluid as well as operating conditions. Values ranging from $200 \mathrm{~W} / \mathrm{K}$ to $400 \mathrm{~W} / \mathrm{K}$ for the heat exchange capacity rate were included in the parameter variation. From Figure 4Figure 3 where the solar collector area of the system was fixed to $36 \mathrm{~m}^{2}$, it can be seen that the heat exchange capacity rate of each module highly affects the solar fraction achieved by the system. With a heat exchange capacity rate of 400 $\mathrm{W} / \mathrm{K}$ it was possible the reach $80 \%$ solar fraction with 7 modules of 150 liters L. If the heat exchange capacity rate was $250 \mathrm{~W} / \mathrm{K} 12$ modules were required to obtain $80 \%$ solar fraction. 


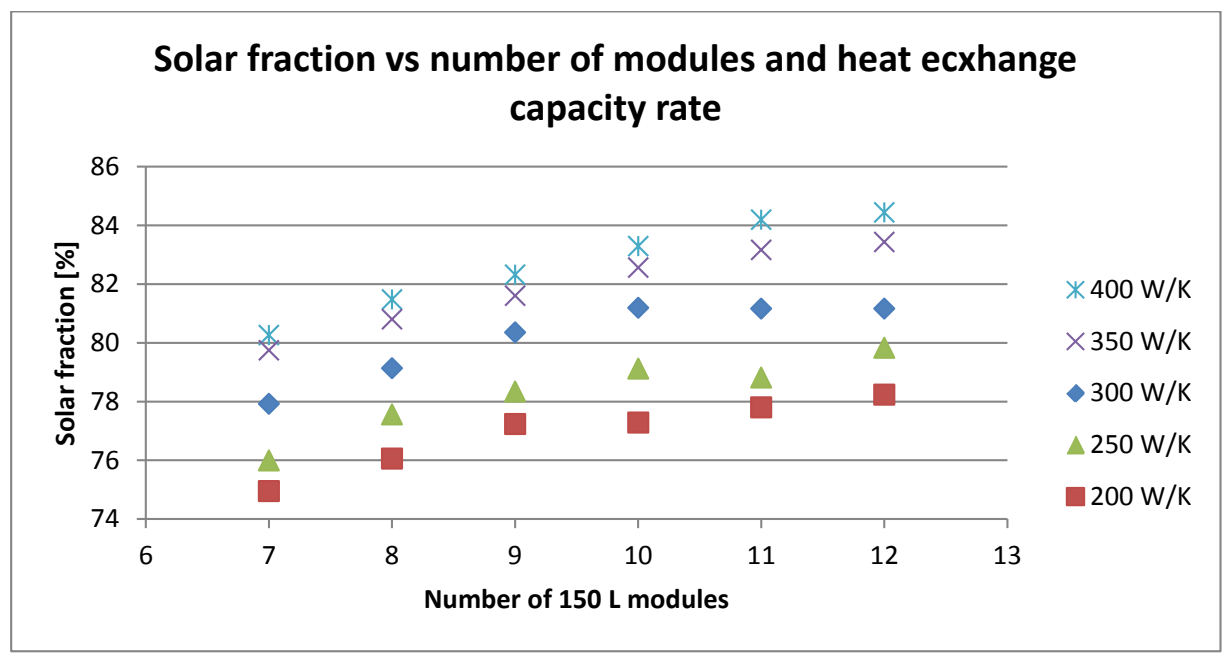

Figure 4. Solar fraction vs number of modules and heat exchange capacity rate for solar combi system with $36 \mathrm{~m}^{2}$ collector area.

The sizes of the individual modules have also shown to have an effect on the yearly performance of the system even if the total PCM volume was kept. Doubling the PCM volume of the modules and assuming the heat exchange capacity rate also doubles due to a larger heat exchanger showed to increase the solar fraction by 7 percentage points. Doubling the PCM volume without increasing the heat exchange capacity rate had almost no effect of the system performance as may be seen in Figure 5 . This indicates that there is a relation between the operation strategy, energy demand and system design which can be optimized for each case.

\section{Solar fraction vs total PCM volume in differently designed modules}

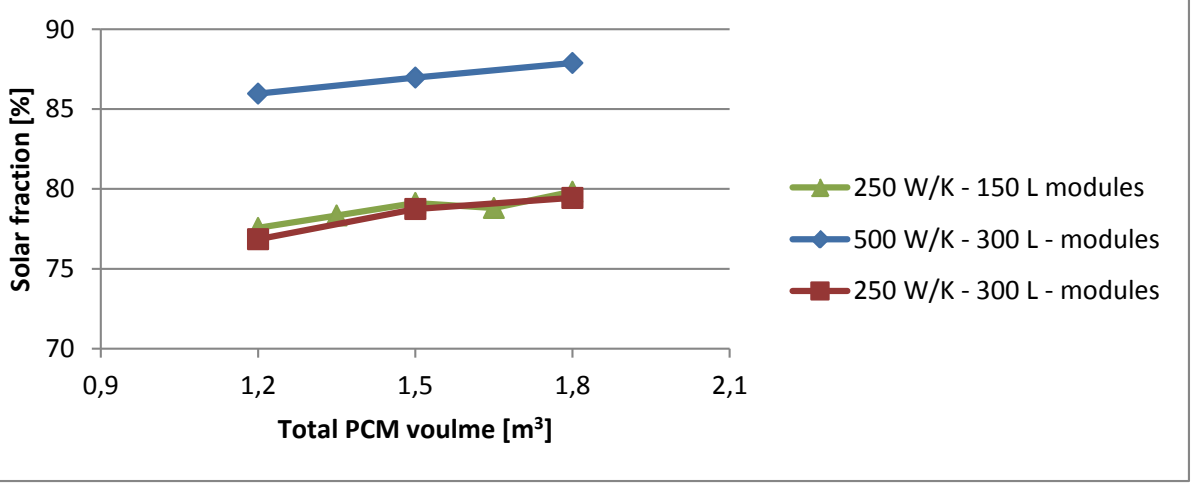

Figure 5 . Solar fraction vs. total PCM volume in differently designed modules.

Formatted: Font: $9 \mathrm{pt}$, Bold, Font color: Accent 1, English (U.S.)

Formatted: Keep with next

Formatted: English (U.S.)

Formatted: Caption

Formatted: English (U.S.) 
modules were varied. Based on the cost of the PCM modules and of the solar collectors an evaluation can be made to choose the optimum system design and size.

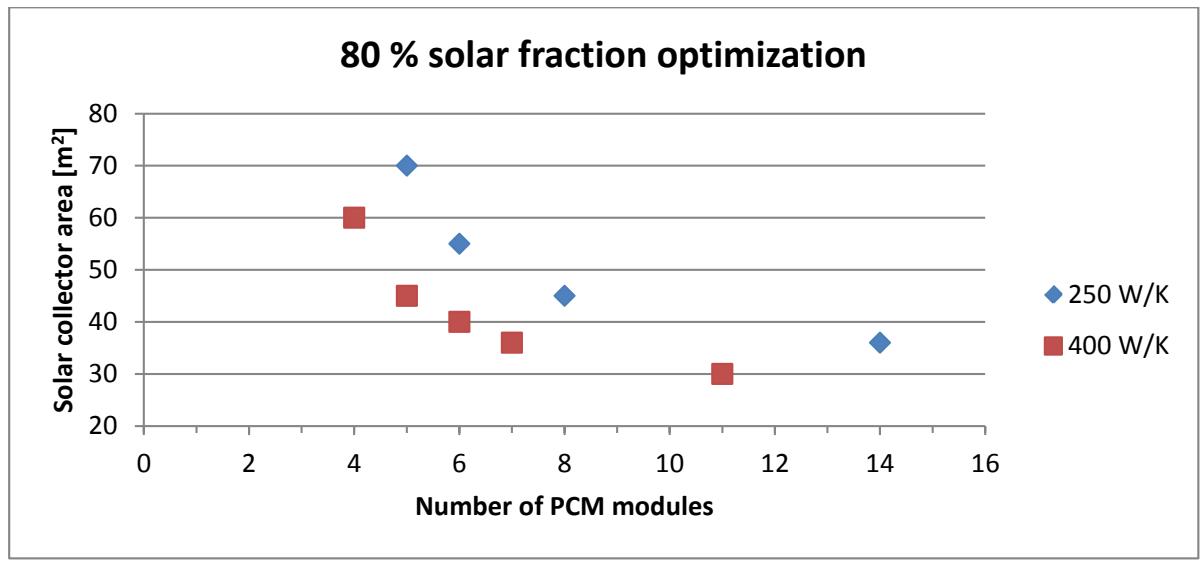

Figure $6.80 \%$ solar fraction for systems with heat exchange capacity rate for the PCM storage of $250 \mathrm{~W} / \mathrm{K}$ and $400 \mathrm{~W} / \mathrm{K}$.

Installation of such PCM storage systems in already built houses also leads to considerations related practically installation possibilities of access and handling. This could lead to restrictions of module size.

\section{Conclusions}

To have a reliable long term heat storage based on stable supercooling of sodium acetate trihydrate a number of problems have to be solved. Capacity loss due to phase separation can be solved by using thickening agents such as carboxyl methyl cellulose (CMC) and Xanthan rubber. The density difference of the sodium acetate trihydrate from the coldest to the hottest state is associated with pressure changes in a storage module. To obtain stable supercooling in large bulks of sodium acetate trihydrate in closed rigid tanks it is essential to operate the PCM chamber with minimal pressure changes. This can e.g. be done by having an expansion volume in the PCM chamber connected to an external expansion vessel without prepressure. The heat exchange capacity rate to and from the PCM can be improved by adding a highly conductive compound such as graphite powder to the PCM combined with a temperature stable thickening agent. The thickening agent has to be stable in the entire temperature interval the storage operates-at. Xanthan rubber has shown to keep its thickening ability up to $90^{\circ} \mathrm{C}$. Cavities in the PCM are formed when the PCM contracts during crystallization. A heat transfer fluid inside the PCM chamber that does not react with the PCM can fill in these gaps and increase the heat exchange capacity rate. Triggering the crystallization of the supercooled sodium acetate can be done by providing a seed crystal or by cooling a small part of the PCM to its minimum level of supercooling e.g. by evaporating $\mathrm{CO} 2$ in a small chamber adjacent to the PCM chamber.

From theoretical consideration it is possible to store up to $230 \mathrm{~kJ} / \mathrm{kg}$ of supercooled sodium acetate trihydrate at $20^{\circ} \mathrm{C}$ if all sensible heat down to $20^{\circ} \mathrm{C}$ can be utilized. A TRNSYS simulation showed that for a passive house in Danish climate it was possible to achieve a solar fraction of $80 \%$ by a solar heating system with $36 \mathrm{~m}^{2}$ solar collector area and 7 PCM modules of 150 liters $\underline{L}$ if the heat exchange capacity rate was 
$400 \mathrm{~W} / \mathrm{K}$. If the heat exchange capacity rate was $250 \mathrm{~W} / \mathrm{K} 12$ modules were required to achieve $80 \%$ solar fraction. Based on this parametric study including system size and heat exchange capacity rate of the module it was obvious that a high heat exchange capacity rate is desired to reach a high solar fraction with smaller system sizes.

\section{Acknowledgements:}

This research was partly funded by the European Commission as part of the Seventh Framework Programme of the European Community for Research, Technological Development and Demonstration Activities under the funding scheme of "Collaborative Project" through the COMTES consortium. Partly by the Danish Energy Agency supporting the joint IEA SHC Task 42/ ECES Annex 29 programme on Compact Thermal Energy Storage. We thank our partners Henry Sørensen from Nilan A/S and Hermann Schranzhofer and Christoph Moser from Graz University of Technology for sharing knowledge and discussions.

\section{References}

[1] S.D. Sharma, K. Sagara, Latent Heat Storage Materials and Systems: A Review, Int. J. Green Energy. 2 (2005) 1-56. doi:10.1081/GE-200051299.

[2] D.N. Nkwetta, F. Haghighat, Thermal energy storage with phase change material - A state-of-the art review, Sustain. Cities Soc. 10 (2014) 87-100. doi:10.1016/j.scs.2013.05.007.

[3] M.K.A. Sharif, a a Al-abidi, S. Mat, K. Sopian, M.H. Ruslan, Review of the application of phase change material for heating and domestic hot water systems, Renew. Sustain. Energy Rev. 42 (2015) 557568. doi:10.1016/j.rser.2014.09.034.

[4] C. Solé, M. Medrano, A. Castell, M. Nogue, H. Mehling, L.F. Cabeza, Energetic and exergetic analysis of a domestic water tank with phase change material, Int. J. ENergy Res. 32 (2008) 204-214. doi:10.1002/er.

[5] T. Wada, F. Kimura, R. Yamamoto, Studies on salt hydrates for latent heat storage. II. Eutectic mixture of pseudo-binary system., Bull. Chem. Soc. Jpn. (1983) 1223-1226.

[6] S. Canbazoğlu, A. Şahinaslan, A. Ekmekyapar, Ý.G. Aksoy, F. Akarsu, Enhancement of solar thermal energy storage performance using sodium thiosulfate pentahydrate of a conventional solar waterheating system, Energy Build. 37 (2005) 235-242. doi:10.1016/j.enbuild.2004.06.016.

[7] K. Nagano, K. Ogawa, T. Mochida, K. Hayashi, H. Ogoshi, Performance of heat charge/discharge of magnesium nitrate hexahydrate and magnesium chloride hexahydrate mixture to a single vertical tube for a latent heat storage system, Appl. Therm. Eng. 24 (2004) 209-220. doi:10.1016/j.applthermaleng.2003.09.002.

[8] A. López-navarro, J. Biosca-taronger, J.M. Corberán, C. Peñalosa, A. Lázaro, P. Dolado, et al., Performance characterization of a PCM storage tank, Appl. Energy. 119 (2014) 151-162. doi:10.1016/j.apenergy.2013.12.041. 
[9] P. Arce, M. Medrano, A. Gil, E. Oró, L.F. Cabeza, Overview of thermal energy storage (TES) potential energy savings and climate change mitigation in Spain and Europe, Appl. Energy. 88 (2011) 27642774. doi:10.1016/j.apenergy.2011.01.067.

[10] A. Abhat, Short Term Thermal Energy Storage, Energy Build. 3 (1981) 49-76.

[11] J. Guion, M. Teisseire, Nucleation of sodium acetate trihydrate in thermal heat storage cycles, Sol. Energy. 46 (1991) 97-100.

[12] P. Hu, D.-J. Lu, X.-Y. Fan, X. Zhou, Z.-S. Chen, Phase change performance of sodium acetate trihydrate with AIN nanoparticles and CMC., Sol. Energy Mater. Sol. Cells. 95 (2011) 2645-2649. doi:10.1016/j.solmat.2011.05.025.

[13] H. Kimura, J. Kai, Phase change stability of sodium acetate trihydrate and its mixtures, Sol. Energy. 35 (1985) 527-534. doi:10.1016/0038-092X(85)90121-5.

[14] G.A. Lane, Solar heat storage latent heat material Vol 1, Boca Raton, Florida, United states, 1983.

[15] J. Stanley, G.L. Hoerner, Reusable heat pack containing supercooled solution and means for activating same, (1978). www.google.com/patents/US4077390 (accessed May 28, 2015).

[16] S. Hirano, T.S. Saitoh, Heat balance of long-term supercooled thermal energy storage, Nihon Enerugi Gakkaishi/Journal Japan Inst. Energy. 80 (2001) 1050-1059.

[17] S. Hirano, S. Takeo, INFLUENCE OF OPERATING TEMPERATURE ON EFFICIENCY OF SUPERCOOLED THERMAL ENERGY STORAGE, in: IECEC 2002 Pap. No. 20040, 2002: pp. 684-689.

[18] S. Hirano, T.S. Saitoh, Performance of Supercooled Thermal Energy Storage Unit with Practial Demensions, 3rd Int. Energy Convers. Eng. Conf. 2 (2005) 1293-1300.

[19] B. Sandnes, J. Rekstad, Supercooling salt hydrates: Stored enthalpy as a function of temperature, Sol. Energy. 80 (2006) 616-625. doi:10.1016/j.solener.2004.11.014.

[20] P.F. Barrett, B.R. Best, Thermal energy storage in supercooled salt mixtures, Mater. Chem. Phys. 12 (1985) 529-536.

[21] B. Zalba, J.M. Marin, L.F. Cabeza, H. Mehling, Review on thermal energy storage with phase change: materials, heat transfer analysis and applications, Appl. Therm. Eng. 23 (2003) 251-283.

[22] S. Furbo, J. Fan, Heat Storage based on a $\mathrm{NaCH} 3 \mathrm{COO}$ Water Mixture for Solar Heating Systems, DTU Civil Engineering, Report SR-12-10 (UK), Kgs. Lyngby, Denmark, 2012.

[23] M.A. Rogerson, S.S.S. Cardoso, Solidification in Heat Packs : I . Nucleation Rate, AIChE J. 49 (2003) 505-515.

[24] L. Wei, K. Ohsasa, Supercooling and Solidification Behavior of Phase Change, ISIJ Int. 50 (2010) 12651269. 
[25] T. Wada, F. Kimura, Y. Matsuo, Studies on salt hydrates for latent heat storage. IV. crystallization in the binary system, Bull. Chem. Soc. Jpn. 56 (1983) 3827-3829.

[26] H. Mehling, L.F. Cabeza, Materials used as PCM in thermal energy storage in buildings: A review, Renew. Sustain. Energy Rev. (2011) 1675-1695. doi:10.1016/j.rser.2010.11.018.

[27] S. Furbo, S. Svendsen, Report on heat storage in a solar heating system using salt hydrates, Therm. Insul. Labotatory, DTU, Kgs. Lyngby, Denmark, Rep. 70. (1977).

[28] S. Furbo, Investigations of Heat Storages with salt hydrate as storage medium based on the extra water principle, Therm. Insul. Labotatory, DTU, Kgs. Lyngby, Denmark, Rep. 80. Meddelelse (1978).

[29] N. Araki, M. Futamura, A. Makino, H. Shibata, Measurements of Thermophysical Properties of Sodium Acetate Hydrate, Internaltional J. Thermophys. 16 (1995) 1455-1466.

[30] L. Desgrosseilliers, P. Allred, D. Groulx, M.A. White, Determination of enthalpy-temperaturecomposition relations in incongruent-melting phase change materials, Appl. Therm. Eng. 61 (2013) 193-197. doi:10.1016/j.applthermaleng.2013.07.019.

[31] L.F. Cabeza, G. Svensson, S. Hiebler, H. Mehling, Thermal performance of sodium acetate trihydrate thickened with different materials as phase change energy storage material, Appl. Therm. Eng. 23 (2003) 1697-1704. doi:10.1016/S1359-4311(03)00107-8.

[32] T. Wada, R. Yamamoto, Y. Matsuo, Heat storage capacity of sodium acetate trihydrate during thermal cycling, Sol. Energy. 33 (1984) 373-375. doi:10.1016/0038-092X(84)90169-5.

[33] H.W. Ryu, S.W. Woo, B.C. Shin, S.D. Kim, Prevention of supercooling and stabilization of inorganic salt hydrates as latent heat storage materials, Sol. Energy Mater. Sol. Cells. 27 (1992) 161-172. doi:10.1016/0927-0248(92)90117-8.

[34] B.M.L. Garay Ramirez, C. Glorieux, E.S. Martin Martinez, J.J. a Flores Cuautle, Tuning of thermal properties of sodium acetate trihydrate by blending with polymer and silver nanoparticles, Appl. Therm. Eng. 61 (2013) 838-844. doi:10.1016/j.applthermaleng.2013.09.049.

[35] G. Lane, Solar heat storage latent heat material Vol 2, CRC, Boca Raton, Florida, United states, 1986.

[36] T. Wada, Studies on sodium acetate trihydrate for latent heat storage, Osaka University, Japan, 1985. hdl.handle.net/11094/2830.

[37] X. Jin, S. Zhang, M. a. Medina, X. Zhang, Experimental study of the cooling process of partiallymelted sodium acetate trihydrate, Energy Build. 76 (2014) 654-660. doi:10.1016/j.enbuild.2014.02.059.

[38] M.A. Rogerson, S.S.S. Cardoso, Solidification in heat packs: I. Nucleation rate, AICHE J. 49 (2003) 505-515. doi:10.1002/aic.690490220.

[39] L.F. Cabeza, J. Roca, M. Nogués, H. Mehling, S. Hiebler, Immersion corrosion tests on metal-salt hydrate pairs used for latent heat storage in the 48 to $588 \mathrm{C}$ temperature range, Mater. Corros. 53 (2002) 902-907. 
[40] M.A. Rogerson, S.S.S. Cardoso, Solidification in Heat Packs : III . Metallic Trigger, AIChE J. 49 (2003) 522-529.

[41] A.E.M. Anthony, P.F. Barrett, B.K. Dunning, Verification of mechanism for nucleating crysrallization of supercooled liquids, Mater. Corros. 25 (1990) 199-205.

[42] P.F. Barrett, D.K. Benson, A mechanism for nucleating supercooled liquids, Mater. Chem. Phys. 20 (1988) 171-178.

[43] W.-B. Ye, D.-S. Zhu, N. Wang, Fluid flow and heat transfer in a latent thermal energy unit with different phase change material (PCM) cavity volume fractions, Appl. Therm. Eng. 42 (2012) 49-57. doi:10.1016/j.applthermaleng.2012.03.002.

[44] M. Medrano, M.O. Yilmaz, M. Nogués, I. Martorell, J. Roca, L.F. Cabeza, Experimental evaluation of commercial heat exchangers for use as PCM thermal storage systems, Appl. Energy. 86 (2009) 20472055. doi:10.1016/j.apenergy.2009.01.014.

[45] A. Heinz, Application of Thermal Energy Storage with Phase Change Materials in Heating Systems, Graz University of Technology, Austria, 2007.

[46] W. Li, J. Mao, L. Wang, L. Sui, Effect of the Additive on Thermal Conductivity of the Phase Change Material, Adv. Mater. Res. 399-401 (2011) 1302-1306. doi:10.4028/www.scientific.net/AMR.399401.1302.

[47] F. Frusteri, V. Leonardi, G. Maggio, Numerical approach to describe the phase change of an inorganic PCM containing carbon fibres, Appl. Therm. Eng. 26 (2006) 1883-1892. doi:10.1016/j.applthermaleng.2006.01.018.

[48] H.K. Shin, M. Park, H.-Y. Kim, S.-J. Park, Thermal property and latent heat energy storage behavior of sodium acetate trihydrate composites containing expanded graphite and carboxymethyl cellulose for phase change materials, Appl. Therm. Eng. 75 (2015) 978-983. doi:10.1016/j.applthermaleng.2014.10.035.

[49] L.F. Cabeza, H. Mehling, S. Hiebler, F. Ziegler, Heat transfer enhancement in water when used as PCM in thermal energy storage, Appl. Therm. Eng. 22 (2002) 1141-1151. doi:10.1016/S13594311(02)00035-2.

[50] D.N. Nkwetta, P.-E. Vouillamoz, F. Haghighat, M. El-Mankibi, A. Moreau, A. Daoud, Impact of phase change materials types and positioning on hot water tank thermal performance: Using measured water demand profile, Appl. Therm. Eng. 67 (2014) 460-468. doi:10.1016/j.applthermaleng.2014.03.051.

[51] K. Seo, S. Suzuki, T. Kinoshita, I. Hirasawa, Effect of Ultrasonic Irradiation on the Crystallization of Sodium Acetate Trihydrate Utilized as Heat Storage Material, Chem. Eng. Technol. 35 (2012) 10131016. doi:10.1002/ceat.201100680.

[52] W. Streicher, J. Bony, S. Citherlet, A. Heinz, P. Pusching, H. Schranzhofer, et al., Simulation Models of PCM Storage Units, IEA Solar Heating and Cooling programme - Task 32 "Advanced storage concepts 
for solar and low energy, Report C5 of Subtask C buildings," Institute of Thermal Engineering Graz University of Technology, Austria, 2008.

[53] J.M. Schultz, S. Furbo, Investigation of heat of fusion storage for solar low energy buildings, Proc. Sol. World Congr. 2005 Bringing Water To World, Incl. Proc. 34th Ases Annu. Conf. Proc. 30th Natl. Passiv. Sol. Conf. Proc. Sol. World Congr. Bringing Water World, Incl. Proc. Ases Annu. 3 (2005) 1833-1838.

[54] Statens Byggeforskningsinstitut, tsbi3, (1993). www.sbi.dk.

[55] Passive House Institute, Passive House Institute, (n.d.). www.passiv.de/en/index.php (accessed May 28, 2015).

[56] J. Schultz, S. Furbo, Solar heating systems with heat of fusion storage with $100 \%$ solar fraction for solar low energy buildings, in: ISES Sol. World Congr. 2007 Proc., 2007: pp. 2721-2725. 